\title{
Extraction Properties of Calix[4]arenes towards Sulphonated Dyes
}

\author{
Muhammad Israr'1, Faiza Faheem², Fozia T. Minhas², Asma Rauf², Saba Rauf ${ }^{3}$, \\ M. Raza Shah'2, Fazal Rahim1, Kiramat Shah ${ }^{2}$, M. I. Bhanger ${ }^{2 *}$ \\ ${ }^{1}$ Department of Chemistry, Hazara University, Mansehra, Pakistan \\ ${ }^{2}$ International Center for Chemical \& Biological Science, University of Karachi, Karachi, Pakistan \\ ${ }^{3}$ NED University of Engineering \& Technology, Karachi, Pakistan \\ Email: *dbhanger2000@gmail.com
}

Received 22 January 2016; accepted 26 February 2016; published 29 February 2016

Copyright (C) 2016 by authors and Scientific Research Publishing Inc.

This work is licensed under the Creative Commons Attribution International License (CC BY).

http://creativecommons.org/licenses/by/4.0/

(c) (i) Open Access

\begin{abstract}
Extraction of sulphonated dyes through supramolecular interaction with calix[4]arene derivatives is being presented here. The selectivity of calixarene derivatives namely piperidine derivative of calix[4]arene (calix-1), 1-methyl piperazine derivative of calix[4]arene (calix-2), and di-methyl amine derivative of calix[4]arene (calix-3) were evaluated initially against reactive red 2 (RR-2), acid black (AB), reactive blue 19 (B-19) and synthetic dye (D-2) by liquid-liquid extraction experiment. The results showed that the above three calixarenes possess excellent complexation abilities toward the selected dyes. The stoichiometric ratio for the calixarene derivatives and dyes was estimated through Job's plot, whereas Hildebrand-Benesi equation was used to calculate formation constant $\left(\mathrm{K}_{\mathrm{s}}\right)$ and molar absorptivity $(\Delta \varepsilon)$ of complexes. The binding association $\left(\mathrm{K}_{\mathrm{a}}\right)$ and dissociation $\left(K_{d}\right)$ constants were calculated by Scatchard plot additionally to further support the complexation data obtained from Hildebrand-Benesi equation. Conversely association constants from, both Hildebrand-Benesi equation and Scatchard plot i.e. $\mathrm{K}_{\mathrm{s}}$ and $\mathrm{K}_{\mathrm{a}}$ favor strong binding interaction between calix-1: D-2, calix-2: B-19, and calix-3: AB complexes. Thus present study adeptly supports the complexation of calixarene derivatives for sulfonated dyes.
\end{abstract}

\section{Keywords}

Calixarene Derivative, Complexation, Job's Plot, Hildebrand and Benesi Equation, Association Constant

\section{Introduction}

The abundant use of dyes in industries namely paper, agriculture, cosmetics, textile, plastic and leather during "Corresponding author.

How to cite this paper: Israr, M., Faheem, F., Minhas, F.T., Rauf, A., Rauf, S., Shah, M.R., Rahim, F., Shah, K. and Bhanger, M.I. (2016) Extraction Properties of Calix[4]arenes towards Sulphonated Dyes. American Journal of Analytical Chemistry, 7, 219-232. http://dx.doi.org/10.4236/ajac.2016.72019 
recent times has significantly produced environment related issues [1]-[4]. Approximately ten thousand commercial dyes are available however, approximately 0.7 million tons of dyes are produced on the annual on global basis [5]. Furthermore, the textile industry releases bulk quantity $(10 \%-15 \%)$ of dyes in comparison to other industries [6] [7]. During coloration process not all synthetic dyes are attached with the fabric consequently they are lost in the effluent [4]. The toxicity of dyes is already reported; even at minuscule level they can cause asthma, rhinitis and dermatitis. The prolong exposure of dye stuff in workers of these industries is associated with serious health troubles such as mutagenicity, genotoxicity and carcinogenicity. Besides this, dyes are also hazardous for aquatic ecosystem and severely affect marine life [8].

Due to the improper waste water treatment by several industries, quantities of dyes (and other pollutants) remain high enough than the safer limits. Additionally dyes are unable to degrade by conventional waste water treatment processes, therefore alternate techniques are required for their remediation. Conventionally adsorption [9], photodegradation [10] [11], membrane separation [1]-[4] [7], electrolytic chemical treatment [12], catalytic processes [13] [14], and ozone treatment [15] are in use for colour removal. Removal of organic pollutants by textile waste is a challenging task due to complex composition and diversity of synthetic procedure used to accelerate new products.

In this context, different supramolecular receptors such as crown ethers, cyclodextrins and calixarenes have been synthesized to study their complexation with selected dyes. Calix[n]arenes are quite promising molecules because of their crown ethers and cyclodextrins type of properties. The molecular scaffold of calix[n]arene serves as receptors for number of ionic and molecular guests. The inclusion cavity of calix[n]arene molecule along with wide upper and narrow lower rims provide suitable site for complexation with molecules of several dyes [16]-[20]. Beside this the functionality of upper and lower rim of calix[n]arene receptor can be modified according to the desired application. A variety of data are published during last decade on the intrinsic interaction between calixarenes and dyes [21]-[26].

The objective of the current study is to examine sequentially the complexation phenomena between calix[4]arene derivatives of diverse functionality and the sulphonated dyes. For this purpose, three calixarene derivatives namely 5,11,17,23-tetrakis( $N$-piperidinomethyl)-25,26,27,28-tetrahydroxycalix[4]arene (calix-1), 5,11,17,23-tetrakis( $N$ '-methyl- $N$-piperazino) methyl)-25,26,27,28-tetrahydroxycalix[4]arene (calix-2), 5,11,17, 23-tetrakis[(dimethylamino) methyl]-25,26,27,28-tetrahydroxy-calix[4]arene (calix-3) (Figure 1) have been synthesized and characterized. These novel calixarene derivatives have large cavity and are likely to form strong interaction with selected dyes. The dyes including reactive red 2 (RR-2), acid black (AB), reactive blue 19 (B-19) and synthetic dye (D-2) (Figure 2) were selected. Detailed studies about complexation of calixarene derivatives with sulphonated dyes in water have been carried out and the results obtained strengthened the idea that it can be exploited for their removal from waste water.

\section{Experimental}

\subsection{Materials}

${ }^{1} \mathrm{H}-\mathrm{NMR}$ spectra were recorded in $\mathrm{CDCl}_{3}$ on a Bruker-ARX 400 (Switzerland) instrument, using TMS as reference. The UV-Vis measurements were conducted on UV-1800 Shimadzu (Kyoto, Japan) Spectrophotometer. Sulphonated dyes i.e. RR-2, AB, B-19 and D-2 were purchased from Acros Organics, China. The HR-FABMS (positive or negative-ion mode) were recorded from JMS HX-110 with a data system and JMS DA-500 mass spectrometers, resp.; $\mathrm{m} / \mathrm{z}$ (rel. \%). Dichloromethane $\left(\mathrm{CH}_{2} \mathrm{Cl}_{2}\right)$ and Dimethyl sulphoxide (DMSO) of analytical grade were used.

\subsection{Synthesis of Calix[4]arene Derivative}

Calixarene derivatives i.e. calix-1, calix-3 and compound (1) were synthesized according to previously published method [27] [28], while the calix-2 was synthesized as follows:

5,11,17,23-tetrakis ( $N$ '-methyl- $N$-piperazino)methyl)-25,26,27,28-tetrahydroxycalix[4]arene (calix-2)

In a $25 \mathrm{ml}$ round bottom flask $0.8 \mathrm{~g}(0.00188 \mathrm{~mol})$ of compound (1) was dissolved in THF (18 ml). After stirring for 5 minutes $1.8 \mathrm{ml} \mathrm{CH} 3 \mathrm{COOH}, 1.4 \mathrm{ml}$ (0.00752 mol) 1-methyl piperazine and $0.4 \mathrm{ml}$ (0.00752 mol) $\mathrm{HCHO}$ was added to it. Then the reaction mixture was stirred at ice cooled condition for $24 \mathrm{~h}$. The reaction was monitored by TLC $\left(10 \% \mathrm{CH}_{3} \mathrm{OH}\right.$ in $\left.\mathrm{CH}_{2} \mathrm{Cl}_{2}\right)$ which showed that almost the reaction was completed. Then the 

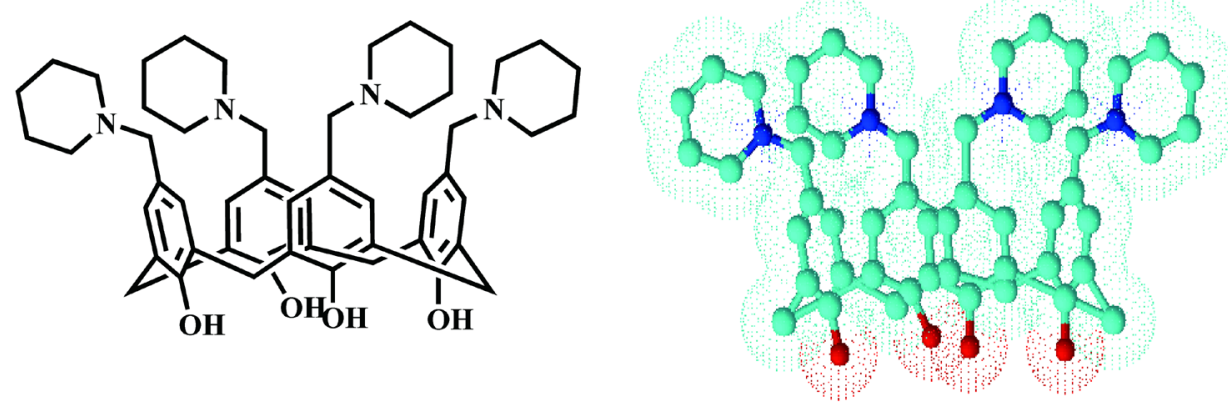

Piperidine Derivative of Calix[4]arene (calix-1)
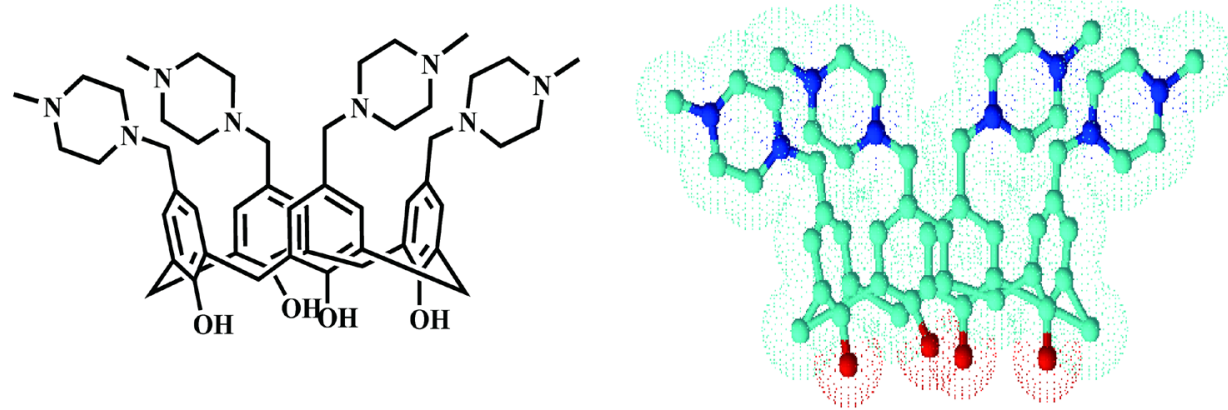

1-Methyl Piperidine Derivative of Calix[4]arene (calix-2)
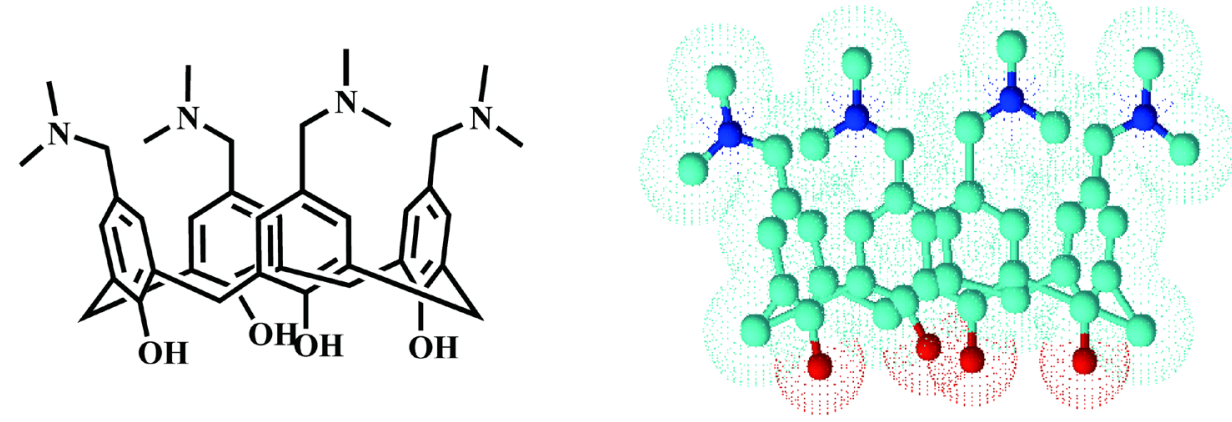

Dimethylamine Derivative of Calix[4]arene (calix-3)

Figure 1. The structural representation of calix[4]arene derivates.

reaction was stopped and THF was removed through rotary evaporator till a viscous material was appeared. The viscous material was dissolved in water and extracted 2 - 3 times with $\left(\mathrm{CH}_{3} \mathrm{CH}_{2}\right)_{2} \mathrm{O}$. Then $10 \% \mathrm{~K}_{2} \mathrm{CO}_{3}$ solution was added to aqueous content in order to neutralize it and caused precipitation. The precipitates were filtered and recrystallized with $\mathrm{CHCl}_{3}$ and the yield obtained was $76 \%$. The recrystallized material was kept in desiccators for drying. FAB positive: $874,{ }^{1} \mathrm{H}-\mathrm{NMR}\left(\mathrm{DMSO}^{-} \mathrm{d}_{6}\right): \delta=6.74$ (s, 8H, ArH) 4.22 (d, $4 \mathrm{H}, J=12 \mathrm{~Hz}, \mathrm{Ar}-\mathrm{CH}_{2}-$ $\mathrm{Ar}$ ), $3.14\left(\mathrm{~d}, 4 \mathrm{H}, J=12 \mathrm{~Hz}, \mathrm{Ar}-\mathrm{CH}_{2}-\mathrm{Ar}\right) 3.10\left(\mathrm{~s}, 8 \mathrm{H}, \mathrm{ArCH}_{2} \mathrm{~N}\right.$ ), $2.26\left(\right.$ br s, $\left.32 \mathrm{H}, \mathrm{NCH}_{2} \mathrm{CH}_{2} \mathrm{~N}\right), 2.12(\mathrm{~s}, 24 \mathrm{H}$, $\left.\mathrm{NCH}_{3}\right)$

\subsection{Liquid/Liquid Extraction}

By following the Pederson procedure $10 \mathrm{~mL}$ of $2.5 \times 10^{-5}$ aqueous dye solution was agitated with $10 \mathrm{~mL}$ of $1 \times$ $10^{-3} \mathrm{M}$ calixarene derivatives at room temperature [29]. The dye concentration was determined using UV-Vis spectrophotometer, the maximum wavelength at which RR-2, AB, B-19 and D-2 absorbs are $539 \mathrm{~nm}, 618 \mathrm{~nm}$, 
<smiles>[R4][R4]#C[R4]</smiles>

Anthraquinone Based Dye<smiles>COCCOc1cccc(Nc2cc(O[Na])c(N)c3c2C(=O)c2ccccc2C3=O)c1</smiles>

Blue 19 (B-19)<smiles>Nc1c(O)cc2cc(O[N+](=O)[O-])c(N=Nc3ccc([N+](=O)[O-])cc3)c(N)c2c1O</smiles>

Acid Black (AB)<smiles>CC1=C(N=Nc2c(N)c(ON)nc3cc(OS(N)(=O)=O)ccc23)C(=O)N(c2ccccc2)CN1C</smiles>

Synthetic dye (D-2)

Figure 2. The structural illustration of dyes.

$590 \mathrm{~nm}$, and $536 \mathrm{~nm}$ respectively. The percentage of extraction was calculated using the following Equation,

$$
E \%=\left[\frac{\left(C_{o}-C\right)}{C_{o}}\right] \times 100
$$

where $C_{o}$ and $C$ are the initial and final concentrations of dye in aqueous solution before and after extraction, respectively. Each reading is taken in triplicate while estimated errors come within range i.e. \pm 0.2 .

\subsection{UV-Visible Spectral Studies of Complexes}

\subsubsection{Jobs Plot Analysis}

The Job's plot was applied by keeping concentrations of calixarene derivatives and dyes same but with variation in their mole ratio [16].

\subsubsection{Benesi-Hildebrand Method}

In order to determine the binding stability of calixarene derivatives with dyes the UV-Vis spectral titration was carried out and complexation parameters were estimated following Benesi-Hildebrand equation.

\subsubsection{Scatchard Plot Analysis}

Scatchard plot analysis was carried to examine the association $\left(\mathrm{K}_{\mathrm{a}}\right)$ and dissociation constant $\left(\mathrm{K}_{\mathrm{d}}\right)$ of complexes.

\section{Results and Discussion}

The complexation ability of calix[4]arene derivatives each bearing different functionality, towards dyes namely 
RR-2, AB, B-19 and D-2 were accomplished in progression. Initially selectivity of calix[4]arene derivatives were furnished via conventional liquid-liquid extraction study. Subsequently, the effect of time, $\mathrm{pH}$ of dyes solution and solvent type were optimized for the extraction of dyes. Further, stoichiometry of calixarene-dye complexes were analyzed through Job’ plot, and Hildebrand-Benesi method along with Scatchard plot were used to deduce the association constant/stability of complexes.

\subsection{Synthesis and Characterizations}

The complexation ability of calix[4]arene derivative for dyes is depended on functionalization at its upper and lower rim, since cavity of calix[4]arene is small in comparison to dye molecules. Thus calix[4]arene derivatives with amine functionality at their upper rims were selected because chemical properties of amines are quite renowned. Seemingly, calix-1 and calix-3 exhibits two types of tertiary amine functional groups, one cyclic and other non-cyclic i.e. $\mathrm{N}$-piperidine and dimethylamine, respectively (Figure 1). To further examine the effect of calix[4]arene functionality on dyes, it was planned to synthesize 1-methyl piperazine derivative of calix[4]arene. The 1-methyl piperazine functionality is related in structure with piperadine by the substitution of one NR group by $\mathrm{CH}_{2}$. Synthetic route for 1-methyl piperazine derivative of calix[4]arene is elaborated in Scheme 1. The compound (1) was treated with 1-methyl piperazine by following Mannich reaction, in the presence of $\mathrm{CH}_{3} \mathrm{COOH}$ and $\mathrm{HCHO}$. Subsequently, calix-2 was obtained in $76 \%$ yield and characterized through FAB-MS and ${ }^{1} \mathrm{H}$ NMR.

\subsection{Liquid-Liquid Extraction}

The selectivity of calixarene derivatives i.e. calix-1, calix-2 and calix-3 for H-shaped, anthraquinone based and heterocyclic based dyes were explored by initially performing conventional liquid-liquid extraction experiments. The structure of dyes (RR-2, AB, B-19 and D-2) is shown in Figure 2. The results from extraction experiment are shown in Figure 3 and Table 1. The extraction efficiency of calix-1, calix-2 and calix-3 was observed for D-2, B-19 and AB respectively, which clearly depict the variation in extraction selectivity of dyes with calix[4]arene derivatives of different functionality. Calix-1 shows highest \% extraction for synthetic dye i.e. D-2 that belongs to heterocyclic class of dyes. However, it extracts dyes of H-shaped class secondly and has less affinity with B-19 dye from anthraquinone based class. The chemistry of complexation involves ionic, hydrogen bonding, dipole-dipole interactions and van der waals interaction between dye and calix[4]arene molecules [16]-[18]. Thus presence of piperidine functionality at the upper rim of calix-1, make it more hydrophobic and suitable for inclusion with D-2.

Furthermore calix-2 reveals appealing facts as well. The \% extraction of D-2 and RR-2 are badly diminished, however $\mathrm{AB}$ shows nominal extraction while it possess superior selectivity for B-19. The hydrophobic interaction in case of piperazine functionality becomes two fold, because of having tertiary amine group $\left(-\mathrm{NR}_{2}\right)$ twice. Consequently, selectivity of calix-2 with B-19 is highest relative to other dyes. Likewise to calix-2, the \% extraction with calix-3 for D-2 and RR-2 are also reduced. Conversely, both AB and B-19 have fairly close \% extraction, however values are not higher as in the case of calix- 1 and calix-2. Probably non-cyclic tertiary amine functionality in calix-3 could not develop enough interaction with the dyes. This observation substantially supports the significance of appropriate functionality at the skeleton of calix[4]arene that can make strong complexation linkages with dyes.

To further study the impact of time on the extraction process, liquid-liquid extraction experiment was repeated with prolong times (Figure 3). The extraction was complete after 3 hrs and no noticeable change was seen further. Clearly, the time has more influence on the \% extraction of less extracted dyes relative to the dye

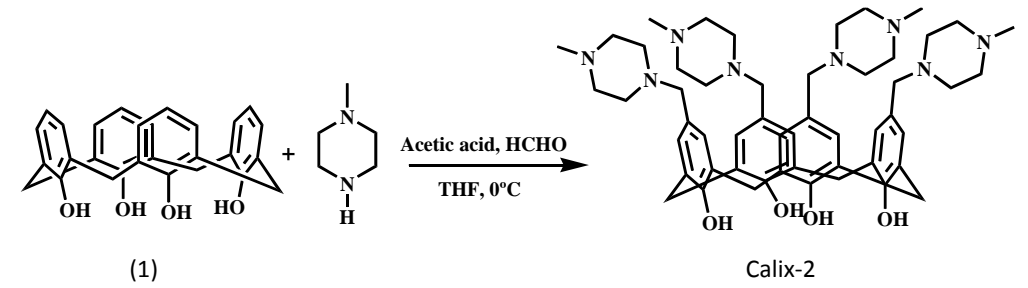

Scheme 1. Synthetic pathway for calix-2. 

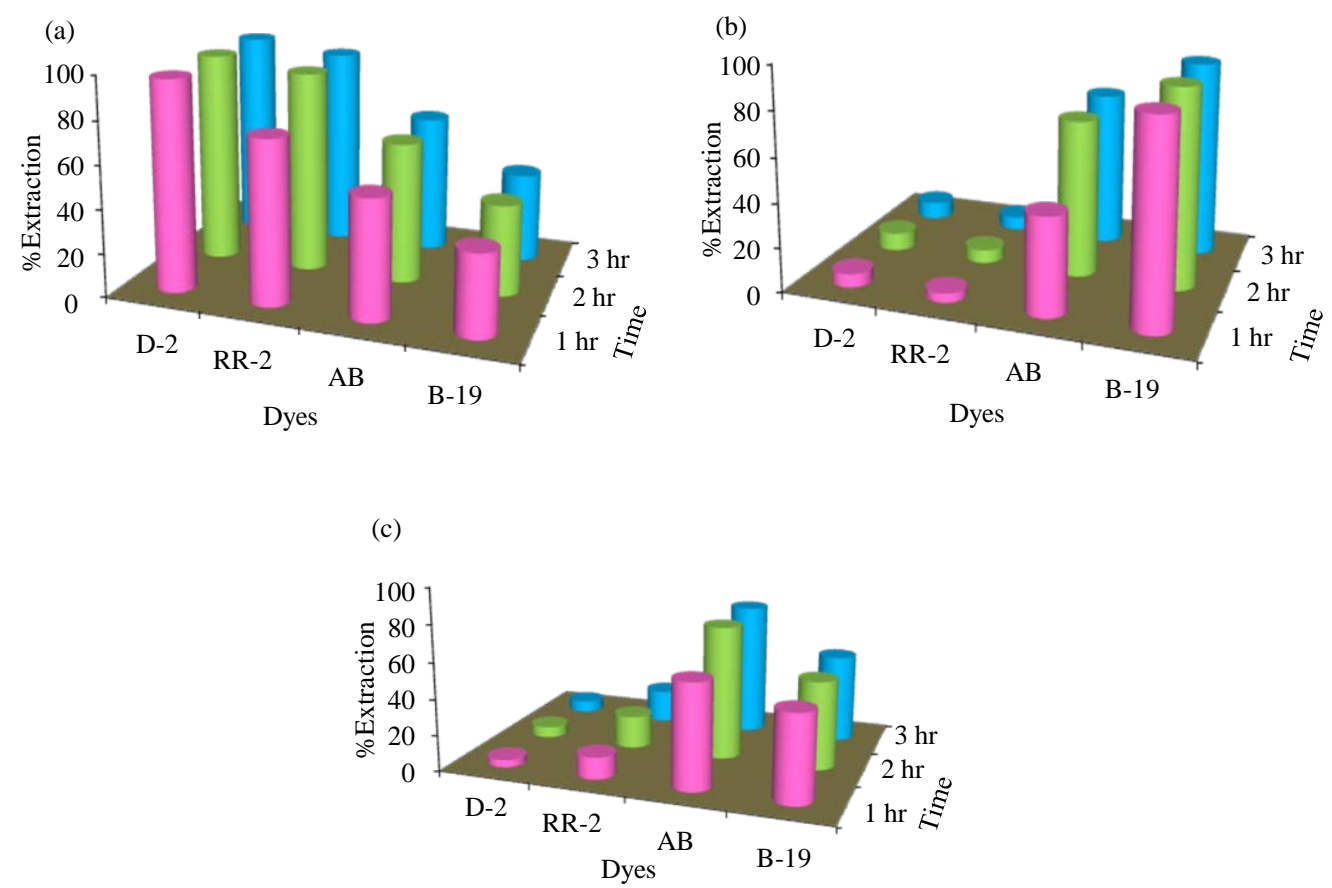

Figure 3. Time study for the extraction of sulphonated dyes, $2.5 \times 10^{-5} \mathrm{M}$ dye solution, $1 \times 10^{-3} \mathrm{M}$ calixarene derivatives (a-c) in $\mathrm{CH}_{2} \mathrm{Cl}_{2}$, at $298 \mathrm{~K}$. (a) calix-1, (b) calix-2 (c) calix-3. (Error may lies in the range of \pm 0.2 ).

Table 1. Collected data for the \% extraction of dyes with calixarene derivatives with respect to time, solvent and $\mathrm{pH}$

\begin{tabular}{|c|c|c|c|c|c|c|c|c|c|c|c|c|}
\hline \multirow{3}{*}{ 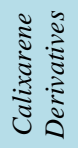 } & \multirow{3}{*}{ Dyes } & \multicolumn{11}{|c|}{$\%$ Extraction } \\
\hline & & \multicolumn{3}{|c|}{ Time Study } & \multicolumn{3}{|c|}{ Solvent Study } & \multicolumn{5}{|c|}{ pH Study } \\
\hline & & $1 \mathrm{hr}$ & $2 \mathrm{hr}$ & $3 \mathrm{hr}$ & $\mathrm{CH}_{2} \mathrm{Cl}_{2}$ & $\mathrm{CHCl}_{3}$ & $\mathrm{CCl}_{4}$ & pH 2 & $p H 4$ & $p H 8$ & pH 10 & pH 12 \\
\hline \multirow{5}{*}{ 离 } & $\mathrm{D}-2$ & 97.0 & 98.0 & 98.0 & 98.0 & 96.0 & 73.0 & 68.0 & 98.1 & 98.1 & 56.5 & 1.85 \\
\hline & RR-2 & 75.0 & 93.0 & 93.0 & 93.0 & 73.5 & 65.0 & 74.0 & 93.3 & 94.7 & 84.1 & 36.1 \\
\hline & $\mathrm{AB}$ & 54.5 & 64.6 & 64.6 & 64.0 & 49.0 & 37.0 & 34.8 & 19.6 & 45.3 & 86.4 & 8.21 \\
\hline & B-19 & 37.0 & 41.6 & 41.6 & 41.0 & 36.6 & 29.0 & 27.6 & 32.9 & 36.2 & 28.8 & 11.5 \\
\hline & D-2 & 6.00 & 8.00 & 8.00 & 6.00 & 4.20 & 2.10 & 2.00 & 5.00 & 4.60 & 1.30 & 0.50 \\
\hline \multirow{3}{*}{ 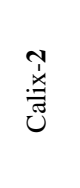 } & RR-2 & 4.00 & 6.00 & 6.00 & 4.00 & 2.80 & 1.30 & 2.30 & 3.00 & 2.10 & 1.00 & 0.40 \\
\hline & $\mathrm{AB}$ & 43.6 & 70.7 & 71.0 & 43.6 & 38.0 & 17.0 & 33.0 & 42.0 & 40.0 & 30.0 & 8.00 \\
\hline & B-19 & 89.9 & 90.0 & 90.0 & 89.9 & 83.0 & 68.0 & 69.0 & 87.0 & 82.0 & 48.0 & 25.0 \\
\hline \multirow{4}{*}{ 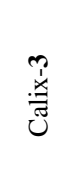 } & $\mathrm{D}-2$ & 4.00 & 6.00 & 6.40 & 4.00 & 2.70 & 0.80 & 3.00 & 3.70 & 2.80 & 2.40 & 0.80 \\
\hline & RR-2 & 12.0 & 18.0 & 18.0 & 12.0 & 9.00 & 4.00 & 6.00 & 9.00 & 8.00 & 4.00 & 2.00 \\
\hline & $\mathrm{AB}$ & 58.0 & 74.0 & 74.0 & 54.0 & 53.0 & 40.0 & 43.0 & 49.0 & 41.0 & 26.0 & 16.0 \\
\hline & B-19 & 48.0 & 48.9 & 49.0 & 48.0 & 32.0 & 29.0 & 37.0 & 43.0 & 35.0 & 21.0 & 10.0 \\
\hline
\end{tabular}

which was already extracted more within $1 \mathrm{hr}$. Apparently, the interaction of dyes with calixarene derivatives increases with the passage of time that results in subsequent enhancement in the \% extraction.

\subsection{PH Influence on Complexation}

The $\mathrm{pH}$ influence on the complexation process is imperative. The surface charge on the functional groups of calixarene moiety and dissociation of dye molecules are fairly dependent on the $\mathrm{pH}$ of solution. Thus to understand 
the complexation phenomena between calixarene derivatives and dyes in detail, extraction experiment was accomplished by varying $\mathrm{pH}$ of aqueous layer from 2 to 12 . Comparative graphical results of all dyes are combined in the Figure 4 and Table 1 and are quite interesting with respect to each dye. The \% extractions of dyes at $\mathrm{pH} 4$ and $\mathrm{pH} 8$ are approximately equal to those at neutral $\mathrm{pH}$ while lower in extreme conditions i.e. $\mathrm{pH} 2$ and $\mathrm{pH} 12$ [17]. This complexation phenomenon of dyes with calixarene derivatives can be justified in terms of electrostatic interaction. At mild acidic conditions, the amine functionality on each calixarene derivative i.e. calix-1, calix-2, and calix-3 become protonated and interact effectively with the negatively charged sulphonated dyes. However, in extreme acidic condition negative charge on all dyes is neutralized by $\mathrm{H}^{+}$ions with subsequent reduction in complexation. Similarly in moderate basic medium, sulfonate groups on all dyes are dissociated and negatively charged dyes involve in complexation with amines of calixarene derivatives. Conversely, under high basic $\mathrm{pH}$ both calixarene derivatives and dye molecules are repelled owing to negative character. Hence, nominal $\mathrm{pH}$ is suitable for maximum complexation between calixarene derivatives and dye molecules which also enlighten green aspect of chosen complexation system.
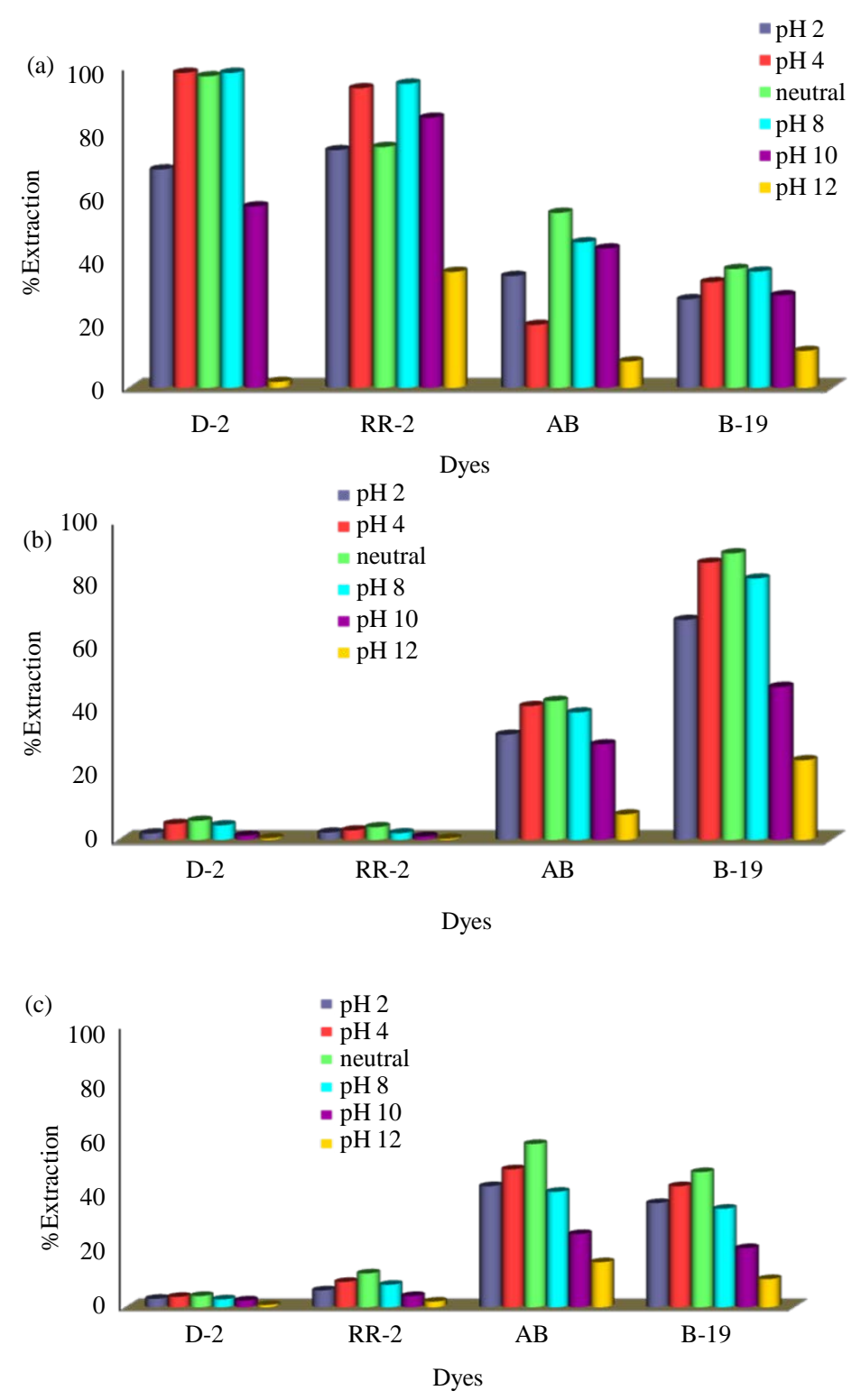

Figure 4. Influence of $\mathrm{pH}$ on the \% extraction of dyes (a) calix-1, (b) calix-2 (c) calix-3. (Error may lie in the range of \pm 0.2 ). 


\subsection{Effect of Solvent}

The nature of solvent has immense influence on the process of extraction. The solvent properties i.e. viscosity, dipole moment, volatility and water immiscibility actually provide stability to the complexation. To estimate the impact of solvent on the extraction ability of calixarene derivatives extractions were carried in $\mathrm{CH}_{2} \mathrm{Cl}_{2}, \mathrm{CHCl}_{3}$, and $\mathrm{CCl}_{4}$. The results are collected in Figure 5. It can be seen that the maximum \% extraction for all dyes is in $\mathrm{CH}_{2} \mathrm{Cl}_{2}$ whereas the trend is as follows $\mathrm{CH}_{2} \mathrm{Cl}_{2}>\mathrm{CHCl}_{3}>\mathrm{CCl}_{4}$. The comparison of solvent properties is shown in the Table 2, to better understand the linkage between solvent type and extraction phenomenon. $\mathrm{CH}_{2} \mathrm{Cl}_{2}$ is proved appropriate solvent for the calixarene derivatives to extract dyes effectively since it possess high dipolar moment, dielectric constant and low viscosity relative to $\mathrm{CHCl}_{3}$, and $\mathrm{CCl}_{4}$ [17]. More specifically polarity in $\mathrm{CH}_{2} \mathrm{Cl}_{2}$ participates in maximum extraction of dyes from aqueous to organic phase owing to stabilization of electrostatic interaction between dye molecule and calixarene derivative.

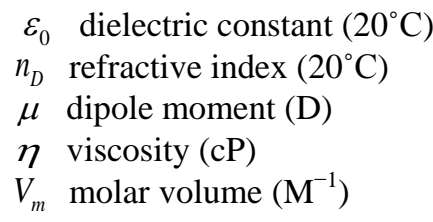

\subsection{Complexation Study}

Basically, the prominent characteristics for dyes complexation in calixarenes are cyclic structure, cavity size and functional groups having ability to make hydrogen bonding and/or hydrophobic interactions. Conversely the hydrophobicity and ionic property of dyes are influential factor for their complexation with calixarenes. Owing to

(a)

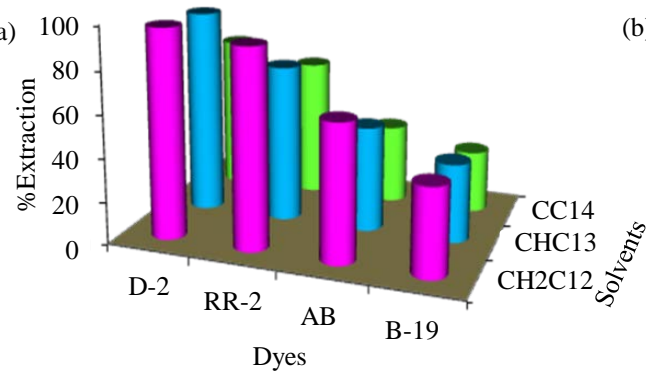

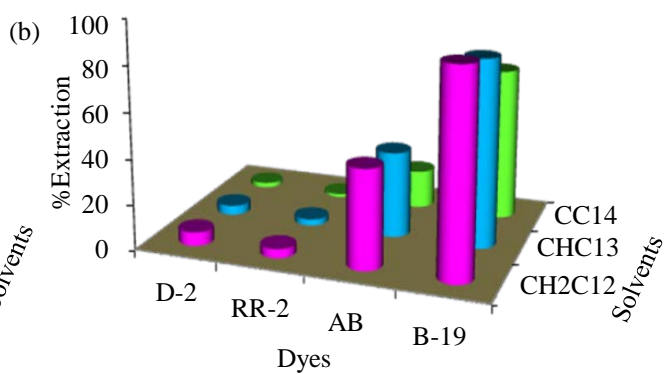

(c)

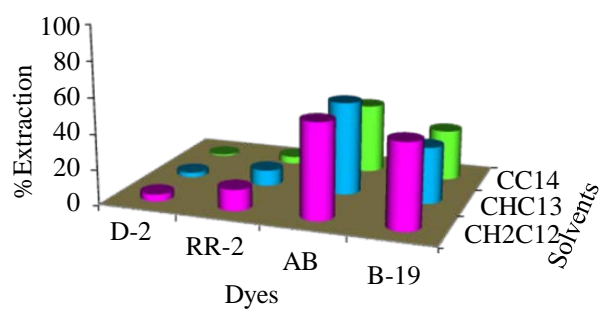

Figure 5. Effect of solvent on \% extraction of dyes (a) calix-1, (b) calix-2 (c) calix-3. (Error may lies in the range of \pm 0.2 ).

Table 2. Physicochemical characteristics of solvents (17).

\begin{tabular}{cccccc}
\hline Solvent & $\varepsilon_{0}$ & $n_{D}$ & $\mu$ & $\eta$ & $V_{m}$ \\
\hline $\mathrm{CH}_{2} \mathrm{Cl}_{2}$ & 9.08 & 1.42 & 1.96 & 0.44 & 64.2 \\
$\mathrm{CHCl}_{3}$ & 4.81 & 1.45 & 1.35 & 0.58 & 96.5 \\
$\mathrm{CCl}_{4}$ & 2.24 & 1.47 & 0 & 0.97 & 96.5 \\
\hline
\end{tabular}


wider central cavity, calix[6]arenes and calix[8]arenes were proved previously excellent adsorbents for azo dyes relative to calix[4]arenes [22]-[25]. Apart from the size of calix[4]arene cavity, introduction of appropriate functionality in calix[4]arene structures could enhance its complexation ability towards dyes magnificently. Concomitantly, Yang et al. presented successful synthesis of calix[4]arene derivative with large s-triazine conjugate group, exhibiting strong complexation affinity towards dyes [18]-[26]. Conclusively, calix[4]arene after adding desired different functional groups could preferentially be utilized for the inclusion complexation with dyes.

Thus the complexation phenomena between calixarene derivatives (calix-1, calix-2, calix-3) and sulphonated dyes (RR-2, AB, B-19 and D-2) were analyzed theoretically. In UV-visible spectroscopy, complex formation is generally assured by shifting in bands of complexes to higher or lower intensity or longer wavelengths in comparison to free ligand (here calixarene derivatives). Moreover, new bands may also appear in complex spectrum depending on the nature of interaction with complexating species, as in the present case. The complexation of calixarene derivatives with dyes was examined in DMSO and is displayed in Figure 6(a), Figure 6(c), Figure 6(e). The concentration of both calixarene derivatives and dyes were kept same i.e. $1 \times 10^{-5} \mathrm{M}$. The strong bands associated with calix-1, calix-2 and calix-3 can be observed at $290 \mathrm{~nm}, 289 \mathrm{~nm}$ and $288 \mathrm{~nm}$, respectively in Figure 6(a), Figure 6(c), Figure 6(e). The band in this region correspond to $\pi \rightarrow \pi^{*}$ transition in calixarene derivatives. The sharp prominent peaks at $536 \mathrm{~nm}, 590 \mathrm{~nm}$, and $618 \mathrm{~nm}$ are obvious in Figure 6(a), Figure 6(c), Figure 6(e) for D-2, B-19 and AB, respectively. In the spectrum of calix-1: D-2 complex, the intensity of calixarene band is augmented at $290 \mathrm{~nm}$ with subsequent reduction in intensity of D-2 band at $536 \mathrm{~nm}$ Figure 6(a). Similarly, band shifts for calix-2: B-19 and calix-3: AB complexes are $3 \mathrm{~nm}$ and $5 \mathrm{~nm}$ respectively. Moreover noticeable reduction in the bands of B-19 $(590 \mathrm{~nm})$ and $A B(618 \mathrm{~nm})$ are seen as well from the spectra of both complexes Figure 6(c), Figure 6(e). These apparent changes in the spectra of complexes are clear indication of successful complexation among calixrene derivatives and sulphonted dyes. Thus, the stoichiometric ratio between calixarene derivatives and dyes was planned to investigate using conventional protocols such as Jobs plot and Benesi-Hildebrand equation.

\subsubsection{Job's Plot}

The stoichiometric ratio among calix-1, calix-2 and calix-3 and sulphonated dyes were examined for their inclusion complexation by using method of continuous variation (Job’s plot) ratio [16] [18] [26]. The solutions were prepared by mixing the different ratios (1:9-9:1) of equimolar concentrations $\left(0.1 \times 10^{-5} \mathrm{M}\right)$ of calixarene derivatives and sulphonated dyes. Afterwards, the graph of absorbance versus mole fraction provides the information about the stoichiometric ratio.

Thus plot of absorbance versus mole ratio for all the dyes are provided in the inserts of Figure 6(a), Figure 6(c), Figure 6(e). For all the complexes (calix 1: D-2, calix 2: B-19, calix 3: AB), the maximum mole fraction value was observed at 0.5 , which evidently proves $1: 1$ ratio of the host-guest complexes.

\subsubsection{Benesi-Hildebrand Equation}

For the spectrophotometric titration, the concentration of calixarene derivatives was kept constant $\left(1 \times 10^{-5} \mathrm{M}\right)$ while the concentration of dyes was increased continuously from $0.0,0.1,0.2,0.3,0.4,0.5,1 \times 10^{-5} \mathrm{M}$. The complex formation constant $\left(\mathrm{K}_{\mathrm{s}}\right)$ was calculated by Benesi-Hildebrand method using Equation 3.

$$
\begin{aligned}
& H+n G \rightarrow H \cdot n G \\
& \frac{1}{\Delta A}=\frac{1}{K_{s} \Delta \varepsilon[H][G]}+\frac{1}{\Delta \varepsilon[H]}
\end{aligned}
$$

Here, $\Delta A$ is the change in the absorbance between the free calixarene derivative and on addition of various concentration of dyes; while, $\Delta \varepsilon$ is the difference in the molar extinction coefficient between the calixarene and calixdye complexes; $[\mathrm{H}]$ represents the host concentration i.e. calixarene; $[\mathrm{G}]$ indicates the guest concentration i.e. dyes. All calix-dye complexes are studied from the plots of $1 / \Delta \mathrm{A}$ values vs $1 /[\mathrm{G}]$ as defined by the BenesiHildebrand Equation [16] [18] [26].

The UV-Vis spectra of calix- 1 , calix-2 and calix- 3 after addition of various concentrations $(0.0,0.1,0.2,0.3$, 0.4, $0.5,1 \times 10^{-5} \mathrm{M}$ ) of respective dyes are elaborated in the Figure 6(b), Figure 6(d), Figure 6(f). The substantial increase in the absorption band of dyes can be visualized in all the spectra of complexes with subsequent 
(a)

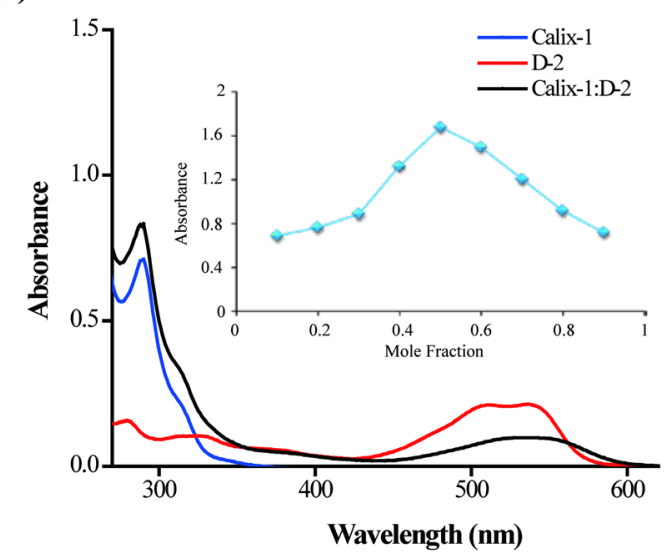

(c)

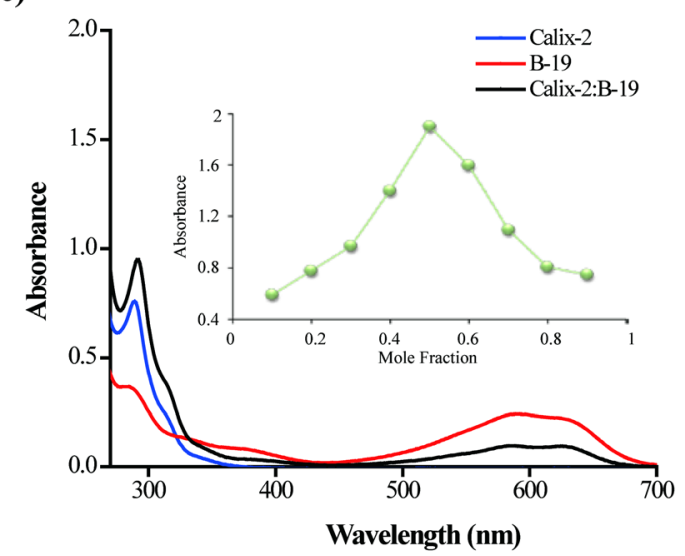

(e)

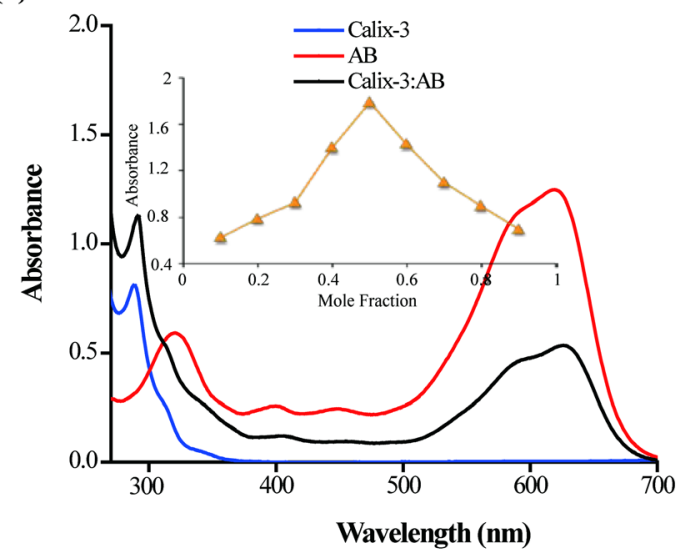

(b)

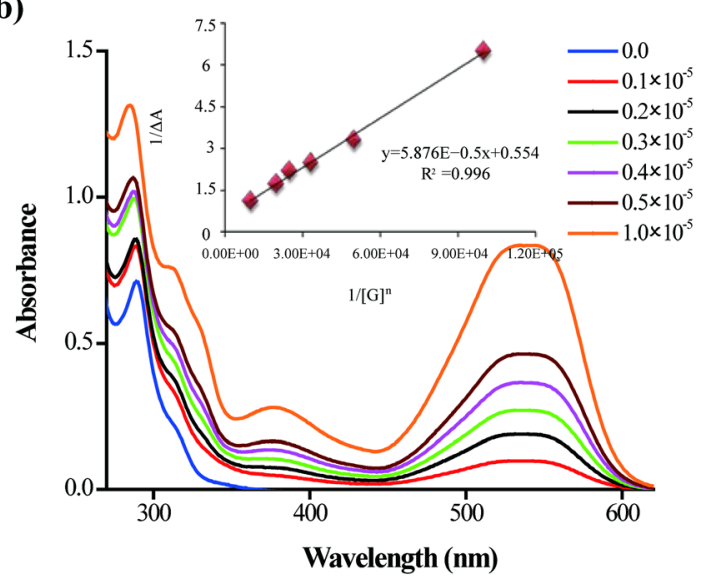

(d)

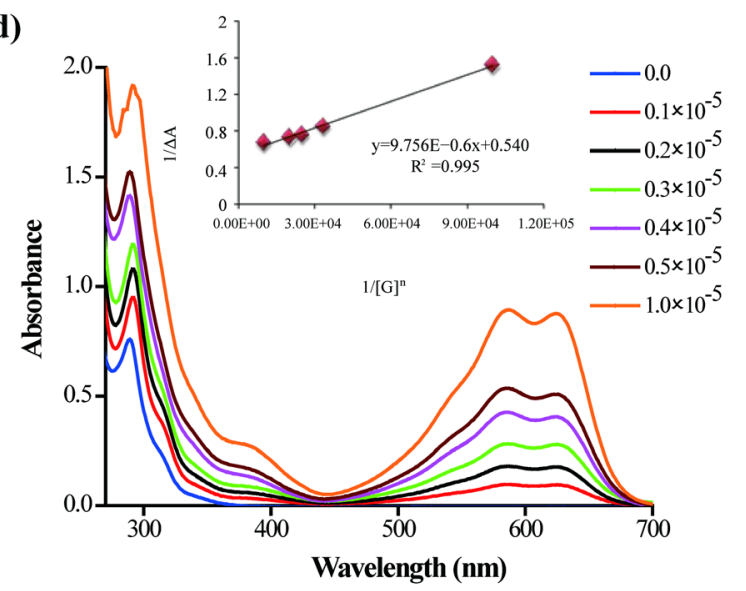

(f)

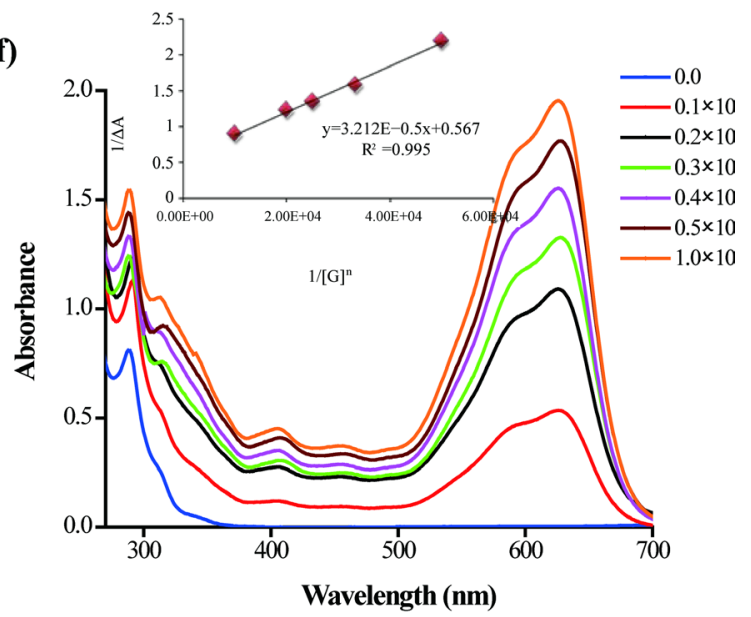

Figure 6. (a), (c), (e) UV-visible response of calixarene derivatives (i.e. calix-1, calix-2 and calix-3) $\left(0.1 \times 10^{-5} \mathrm{M}\right)$ before and after the addition of dyes whereas insert shows the Job's plot of respective calixarene derivative and dyes (b), (d), (f) UV-visible response calixarene derivatives (i.e. calix-1, calix-2 and calix-3) $\left(1 \times 10^{-5} \mathrm{M}\right)$ with the various equivalents of dyes, whereas insert shows the Benesi-Hildebrand plot of respective complex.

rise in the dye concentration. This pattern highlights the complexation of dyes with calixarene derivatives through van der Waals interactions. Since the band in the region $285 \mathrm{~nm}-300 \mathrm{~nm}$ corresponds to the aromatic core of calixarene moiety, therefore changes associated with this region in the spectra of complexes point towards endo-complexation. 
The association constants $\left(\mathrm{K}_{\mathrm{s}}\right)$ and correlation coefficients $\left(\mathrm{R}^{2}\right)$ were calculated by Benesi-Hildebrand equation from the UV-Vis spectral titration data to explore further the binding behavior between calixarene derivatives and dyes. Inserts in the Figure 6(b), Figure 6(d), Figure 6(f) shows the linear plots of $1 / \Delta A$ vs $1 /[G]^{\mathrm{n}}$ with regression coefficients $\left(\mathrm{R}^{2}\right)$ values close to 1 that corroborate binding ratio $(\mathrm{n})=1$ as well. The calculated results are given in Table 3. The validation of experimental measurements was established by calculating the standard deviation $\sigma$ for replicated experiment of each host-guest complexation. Conversely, the higher values of $\mathrm{K}_{\mathrm{s}}$ from Benesi-Hildebrand equation suggest the strong complexation between calix-1: D-2, calix-2: B-19 and calix-3: $\mathrm{AB}$ respectively.

\subsubsection{Scatchard Plot}

The association $\left(K_{a}\right)$ and dissociation constant $\left(K_{d}\right)$ of complexes were calculated by another common method i.e. Scatchard plot analysis:

$$
r /[D]_{\text {free }}=n K_{a}-r K_{a} \text { or } r /[D]_{\text {free }}=n / K_{d}-r / K_{d}
$$

where "r" is the ratio of concentration of bound dye to the total concentration of available calixarene derivative (bound and unbound), $[D]$ is the concentration of free dyes, $\mathrm{n}$ is the no. of binding sites per calixarene derivative, $K_{a}$ and $K_{d}$ are association and dissociation constant respectively obtained from plot of $r /[D]_{\text {free }}$ vs $r$ [30] [31]. Since, experimental parameters used in Scatchard plot are " $[D]_{\text {freee }}$ " the concentration of free dyes and " $r$ " ratio of concentration of bound dye to the total concentration of available calixarene derivatives (bound and unbound).

Thus initially non-linear plots having convex curve was obtained by plotting $r$ vs $[D]_{\text {free }}$ (Figure 7(a), Figure 7(b)). Subsequently, the association $\left(\mathrm{K}_{\mathrm{a}}\right)$ and dissociation $\left(\mathrm{K}_{\mathrm{d}}\right)$ binding constants for the dyes on the calixarene receptors can easily be calculated by plotting $r /[D]_{\text {free }}$ vs $r$ (Figure 7(a), Figure 7(b)). Only the Scatchard plots of calix-3: AB is presented here as model example whereas plots of other complexes left to avoid bulkiness.

It has to be observed that association constant calculated from Scatchard plot is slightly (an order of magnitude) greater than Benesi-Hildebrand plot (Table 3). Binding constants from both methods i.e. $\mathrm{K}_{\mathrm{s}}$ and $\mathrm{K}_{\mathrm{a}}$ clearly shows remarkable affinity between sulphonated dyes and calixarene derivatives.

\subsection{Mechanism}

Dyes can make specific interaction with calixarene derivatives through endo- or exo-complexation, owing to the nature of interaction. The active groups in dyes are sulfo, hydroxyl and azo while cavity in calixarene also play an important role for making particular interaction with dyes. Figure 8 illustrates the graphical representation of calix-1: D-2, calix-2: B-19, and calix-3: AB complexes. The active piperadine, piperazine and tertiary amine functionality in calix-1, calix-2 and calix-3 along with central aromatic cavity encapsulate dyes among themselves.

Table 3. Association constant $\left(\mathrm{K}_{\mathrm{s}}, \mathrm{K}_{\mathrm{a}}\right)$ and molar absorptivity $(\Delta \varepsilon)$ for Complexation of Calixarenes with Dyes.

\begin{tabular}{|c|c|c|c|c|c|}
\hline \multirow{3}{*}{ Complexes } & $\Delta \varepsilon^{\mathrm{a}}$ & $\mathrm{K}_{\mathrm{s}}$ & \multirow{3}{*}{$\mathrm{R}^{2 \mathrm{~b}}$} & $\mathrm{~K}_{\mathrm{a}}$ & $\mathrm{K}_{\mathrm{d}}$ \\
\hline & $\times 10^{4}$ & $\times 10^{4}$ & & $\times 10^{5}$ & $\times 10^{-6}$ \\
\hline & $\mathrm{M}^{-1} \cdot \mathrm{cm}^{-1}$ & $\mathrm{M}^{-1}$ & & $\mathrm{M}^{-1}$ & M \\
\hline Calix-1:D-2 & $\begin{array}{c}2.000 \\
( \pm 0.001)\end{array}$ & $\begin{array}{c}4.999 \\
( \pm 0.004)\end{array}$ & 0.996 & 0.212 & 0.472 \\
\hline Calix-2:B-19 & $\begin{array}{c}3.691 \\
( \pm 0.041)\end{array}$ & $\begin{array}{c}5.417 \\
( \pm 0.061)\end{array}$ & 0.995 & 2.91 & 3.43 \\
\hline Calix-3:AB & $\begin{array}{c}3.605 \\
( \pm 0.067)\end{array}$ & $\begin{array}{c}1.849 \\
( \pm 0.035)\end{array}$ & 0.996 & 7.13 & 1.40 \\
\hline
\end{tabular}

(a) Molar absorptivity for Calixarene-dye complexes, (b) Plot $1 /[\mathrm{G}]^{\mathrm{n}}$ against $1 / \Delta \mathrm{A}$ with high correlation coefficient value, and $\mathrm{K}_{\mathrm{s}}$ is association constant from B-H equation, whereas $\mathrm{K}_{\mathrm{a}}$, and $\mathrm{K}_{\mathrm{d}}$ represents association and dissociation constants from scatchard plots respectively. 

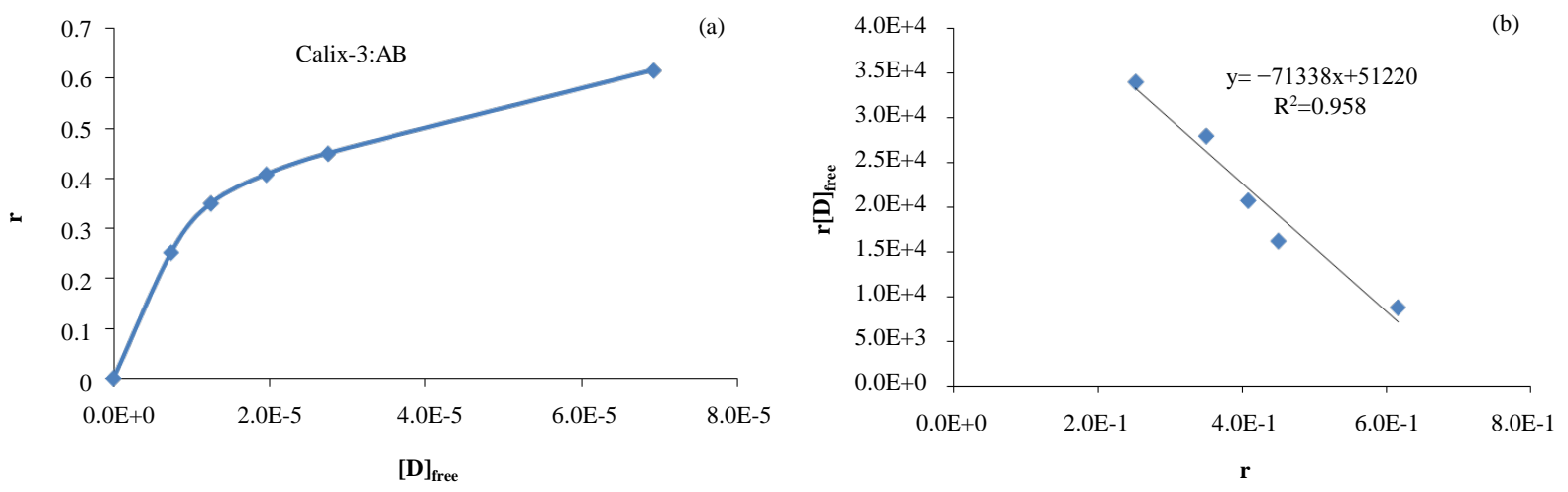

Figure 7. (a) Non-linear form of scatchard plot, (b) Linear form of scatchard plot of Calix-3: ab complex.

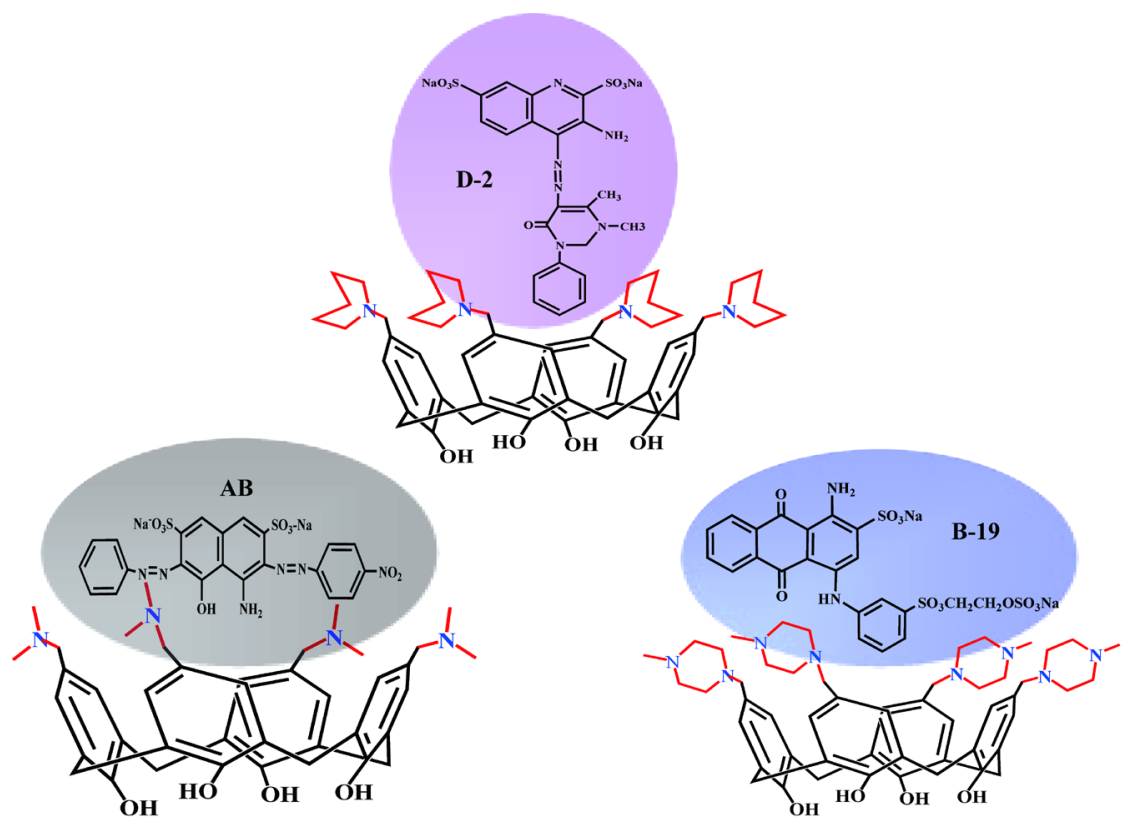

Figure 8. Graphical description of calixarene-dye complexation mechanism.

\section{Conclusion}

The complexion behavior of calixarene derivatives towards sulfonated dyes is optimized in the present study. The results have proven that the above three calixarenes possess excellent complexation abilities toward these dyes. Influence of time, solvent and $\mathrm{pH}$ on the extraction of dyes was determined using simple liquid-liquid extraction experiments. The maximum dye extraction was observed within $1 \mathrm{hr}$, in $\mathrm{CH}_{2} \mathrm{Cl}_{2}$ and at pH 4 . Furthermore, the stoichiometry of calix[4]arene complexes was examined by following Job's plot and Benesi-Hildebrand equation. The obtained 1:1 complexation ratio between calixarene and dyes was also verified by Scatchard plot analysis. The calculated association $\left(\mathrm{K}_{\mathrm{a}}\right)$ and dissociation $\left(\mathrm{K}_{\mathrm{d}}\right)$ binding constants for the complexes from both the methods are in agreement and unambiguously explain the noteworthy complexation between calixarenes and dyes. The outcome of this work supports the idea that it can be exploited for the removal of such dyes from industrial waste water.

\section{Acknowledgements}

We would like to express our thanks to Prof. Dr. Muhammad Iqbal Chaudhary, Director, International Center for Chemical \& Biological Sciences, University of Karachi, Pakistan for providing facilities to conduct this work. 


\section{References}

[1] Salima, A., Ounissa, K.-S., Lynda, M. and Mohamed, B. (2012) Cationic Dye (MB) Removal Using Polymer Inclusion Membrane (PIMs). Procedia Engineering, 33, 38-46. http://dx.doi.org/10.1016/j.proeng.2012.01.1174

[2] Daas, A. and Hamdaoui, O. (2010) Extraction of Anionic Dye from Aqueous Solutions by Emulsion Liquid Membrane Journal of Hazardous Materials, 178, 973-981. http://dx.doi.org/10.1016/j.jhazmat.2010.02.033

[3] Muthuraman, G. and Ibrahim. M. (2013) Use of Bulk Liquid Membrane for the Removal of Cibacron Red FN-R from Aqueous Solution Using TBAB as a Carrier. Journal of Industrial and Engineering Chemistry, 19, 444-449. http://dx.doi.org/10.1016/j.jiec.2012.08.025

[4] Muthuraman, G., Palanivelu, K. and Teng, T.T. (2010) Transport of Cationic Dye by Supported Liquid Membrane Using D2EHPA as the Carrier. Coloration Technology, 126, 97-102. http://dx.doi.org/10.1111/j.1478-4408.2010.00233.x

[5] Praveen Kumar, G.N., Bhat Sumangala, K. (2012) Decolorization of Azo Dye Red 3BN by Bacteria. International Research Journal of Biological Sciences, 1, 46-52.

[6] Madaeni, S.S., Jamali, Z. and Islami, N. (2011) Highly Efficient and Selective Transport of Methylene Blue through a Bulk Liquid Membrane Containing Cyanex 301 as Carrier. Separation and Purification Technology, 81, 116-123. http://dx.doi.org/10.1016/j.seppur.2011.07.004

[7] Nisola, G. M., Cho, E., Beltran, A. B., Han, M., Kim, Y. and Chung, W.-J. (2010) Dye/Water Separation through Supported Liquid Membrane Extraction. Chemosphere, 80, 894-900. http://dx.doi.org/10.1016/j.chemosphere.2010.05.003

[8] Ho, Y.-S., Chiang, T.-H. and Hsueh, Y.-M. (2005) Removal of Basic Dye from Aqueous Solution Using Tree Fern as a Biosorbent. Process Biochemistry, 40, 119-124. http://dx.doi.org/10.1016/j.procbio.2003.11.035

[9] Şuteu, D., Zaharia, C. and Rusu, G. (2010) Reactive Dye Removal from Aqueous Solution by Sorption on Modified Ash. Cercetări Agronomice în Moldova, XLIII, 59-65.

[10] Mahmoud, M.A., Poncheri, A., Badr, Y. and Abd El Wahed, M.G. (2009) Photocatalytic Degradation of Methyl Red Dye. South African Journal of Science, 105, 299-303.

[11] Razaee, A., Ghaneian, M.T., Haashemian, S.J., Moussavi, G.H., Ghanizedeh, G.H. and Hajizadeh, E. (2008) Photochemical Oxidation of Reactive Blue-19 Dye (RB-19) in Textile Wastewater by $\mathrm{UV} / \mathrm{K}_{2} \mathrm{~S}_{2} \mathrm{O}_{8}$ Process. Iranian Journal of Environmental Health Science \& Engineering, 5, 95-100.

[12] Luo, G.S., Yu, M.J., Jian, W.B., Zhu, S.L. and Dai, Y.Y. (1999) Electroextraction Separation of Dyestuffs. Separation Science and Technology, 34, 781-791. http://dx.doi.org/10.1080/01496399908951145

[13] Liu, H.-L. and Chiou, Y.-R. (2006) Optimal Decolorization Efficiency of Reactive Red 239 by UV/ZnO Photocatalytic Process. Journal of the Chinese Institute of Chemical Engineers, 37, 289-298.

[14] Clark, T., Bruce, M. and Anderson, S. (1994) Decolorisation of Extraction Stage Bleach Plant Effluent by Combined Hypochlorite Oxidation and Anaerobic Treatment. Water Science \& Technology, 29, 421-432.

[15] Solozhenko, E.G., Soboleva, N.M. and Goncharuk, V.V. (1995) Decolourization of Azo Dye Solutions by Fenton's Oxidation. Water Research, 29, 2206-2210. http://dx.doi.org/10.1016/0043-1354(95)00042-J

[16] Memon, F.N. and Memon, S. (2012) A Versatile Source for the Recovery of Reactive Blue-19 Dye from Industrial Wastewater. Pakistan Journal of Analytical \& Environmental Chemistry, 13, 62-72.

[17] Memon, F.N., Memon, S. and Minhas, F.T. (2014) Rapid Transfer of Methyl Red Using Calix[6]arene as a Carrier in a Bulk Liquid Membrane. Comptes Rendus Chimie, 17, 577-585. http://dx.doi.org/10.1016/j.crci.2013.09.015

[18] Yang, F., Zhang, Y., Guo, H. and Wei, X. (2013) Highly Efficient Liquid Membrane Transport of Dyes Using Calix[4]arene-Linked Triphenylene Dimers as Carriers. Separation Science and Technology, 48, 1565-1571. http://dx.doi.org/10.1080/01496395.2012.745875

[19] Gubbuk, H. and Gungor, O. (2014) Transport of Methylene Blue through Bulk Liquid Membrane Containing Calix[8]arene Derivative. Desalination and Water Treatment, 52, 5575-5582. http://dx.doi.org/10.1080/19443994.2013.814332

[20] Gungor, O., Yilmaz, A., Memon, S. and Yilmaz, M. (2008) Evaluation of the Performance of Calix[8]arene Derivatives as Liquid Phase Extraction Material for the Removal of Azo Dyes. Journal of Hazardous Materials, 158, 202-207. http://dx.doi.org/10.1016/j.jhazmat.2008.01.060

[21] Ozmen, E.Y., Sirit, A. and Yilmaz, M. (2007) A Calix[4]arene Oligomer and Two Beta-Cyclodextrin Polymers: Synthesis and Sorption Studies of Azo Dyes. Journal of Macromolecular Science, Part A: Pure and Applied Chemistry, 44, 167-173. http://dx.doi.org/10.1080/10601320601031333

[22] Yilmaz, A., Yilmaz, E., Yilmaz, M. and Bartsch, A.R. (2007) Removal of Azo Dyes from Aqueous Solutions Using Calix[4]arene and $\beta$-Cyclodextrin. Dyes and Pigments, 74, 54-59. http://dx.doi.org/10.1016/j.dyepig.2006.01.011 
[23] Kamboh, M.A., Solangi, I.B., Sherazi, S.T.H. and Memon, S. (2011) A Highly Efficient Calix[4]arene Based Resin for the Removal of Azo Dyes. Desalination, 268, 83-89. http://dx.doi.org/10.1016/j.desal.2010.10.001

[24] Kamboh, M.A., Solangi, I.B., Sherazi, S.T.H. and Memon, S. (2011) Synthesis and Application of p-tert-butylcalix[8]arene Immobilized Material for the Removal of Azo Dyes. Journal of Hazardous Materials, 186, 651-658. http://dx.doi.org/10.1016/j.jhazmat.2010.11.058

[25] Chen, M., Shang, T., Fang, W. and Diao, G. (2011) Study on Adsorption and Desorption Properties of the Starch Grafted p-tert-butyl-calix[n]arene for Butyl Rhodamine B Solution. Journal of Hazardous Materials, 185, 914-921. http://dx.doi.org/10.1016/j.jhazmat.2010.09.107

[26] Yang, F., Liu, W., Xie, J., Bai, X. and Guo, H. (2013) Novel Deep-Cavity Calix[4]arene Derivatives with Large $s$-Triazine Conjugate Systems: Synthesis and Complexation for Dyes. Journal of Inclusion Phenomena and Macrocyclic Chemistry, 76, 311-316. http://dx.doi.org/10.1007/s10847-012-0200-2

[27] Gutsche, C.D. and Nam, K.C. (1988) Calixarenes. 22. Synthesis, Properties, and Metal Complexation of Aminocalixarenes. Journal of the American Chemical Society, 110, 6153-6162. http://dx.doi.org/10.1021/ja00226a034

[28] Gutsche, C.D. and Lin, L.G. (1986) Calixarene 12: The Synthesis of Functionalized Calixarene. Tetrahedron, 42, 1633-1640. http://dx.doi.org/10.1016/S0040-4020(01)87580-3

[29] Pedersen, C.J. (1968) Ionic Complexes of Macrocyclic Polyethers. Federation Proceedings, 27, 1305-1309.

[30] Bordbar, A.K., Saboury A.A. and Moosavi-Movahedi, A.A. (1996) The Shapes of Scatchard Plots for Systems with Two Sets of Binding Sites. Biochemical Education, 24, 172-175. http://dx.doi.org/10.1016/0307-4412(95)00122-0

[31] Mareeswaran, P.M., Prakash, M., Subramanian V. and Rajagopal, S. (2012) Recognition of Aromatic Amino Acids and Proteins with $p$-Sulfonatocalix[4]arene-A Luminescence and Theoretical Approach. Journal of Physical Organic Chemistry, 25, 1217-1227. http://dx.doi.org/10.1002/poc.2996 